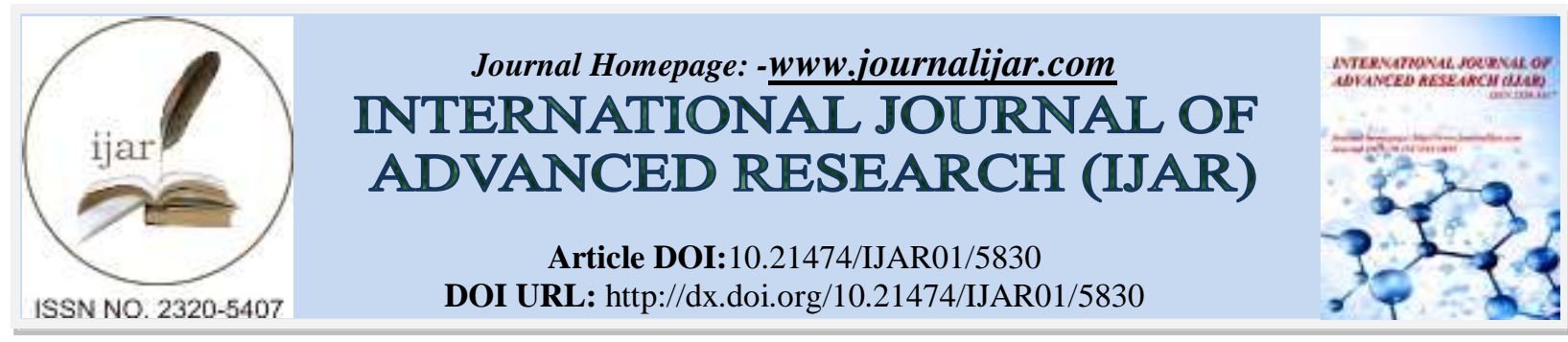

RESEARCH ARTICLE

\title{
ACCEPTANCE AND COMMITMENT THERAPY - A CONTEXTUAL APPROACH TO ADOLESCENTS SOCIAL EMOTIONAL INTELLIGENCE.
}

\author{
M. Abirami. \\ Asst professor, phd scholar maher university.
}

\section{Manuscript Info}

Manuscript History

Received: 11 September 2017

Final Accepted: 13 October 2017

Published: November 2017

\section{Abstract}

Copy Right, IJAR, 2017,. All rights reserved.

\section{Introduction:-}

Adolescence is a critical period for mental, social, and emotional wellbeing and development. During adolescence, the brain undergoes significant developmental changes, establishing neural pathways and behavior patterns that will last into adulthood. Because their brains are still developing, adolescents are particularly receptive to the positive influences of youth development strategies, social and emotional learning, and behavioral modeling. But adolescents' developing brains, coupled with hormonal changes, make them more prone to depression and more likely to engage in risky and thrill-seeking behaviors than either younger children or adults.

Poor mental health can have important effects on the wider health and development of adolescents and is association with several health and social outcomes such as higher alcohol, tobacco and illicit substances use, adolescent pregnancy, school dropout and delinquent behaviors. There is growing consensus that healthy development during childhood and adolescence contributes to good mental health and can prevent mental health problems.

SOCIAL EMOTIONAL INTELLIGENCE is "the ability to monitor one's own and others' feelings and emotions, to discriminate among them and to use this information to guide one's thinking and actions."

Psychologists, medical practitioners, psychotherapists, educators, and other professionals have known for a long time that thoughts and feelings influence each other. Both thoughts and feelings are involved in shaping a person's behavior. Brain research in the last three decades has established that thinking and feeling originate from separate centers of the brain. The centers have been termed the "thinking mind" and the "emotional mind" respectively. The thinking mind is located in the cortex part of the brain while the emotional mind is in the area of the brain known as the limbic system. In particular, the amygdala in the limbic system is the structure that stores emotional experiences associated with various events. That structure is, therefore, the emotional center.

Acceptance and Commitment Therapy (ACT) is a type of psychotherapy that helps you accept the difficulties that come with life. Acceptance and Commitment Therapy (ACT) is a unique empirically based psychological intervention that uses acceptance and mindfulness strategies, together with commitment and behavior change strategies, to increase psychological flexibility.

Psychological flexibility means contacting the present moment fully as a conscious human being, and based on what the situation affords, changing or persisting in behavior in the service of chosen values. 


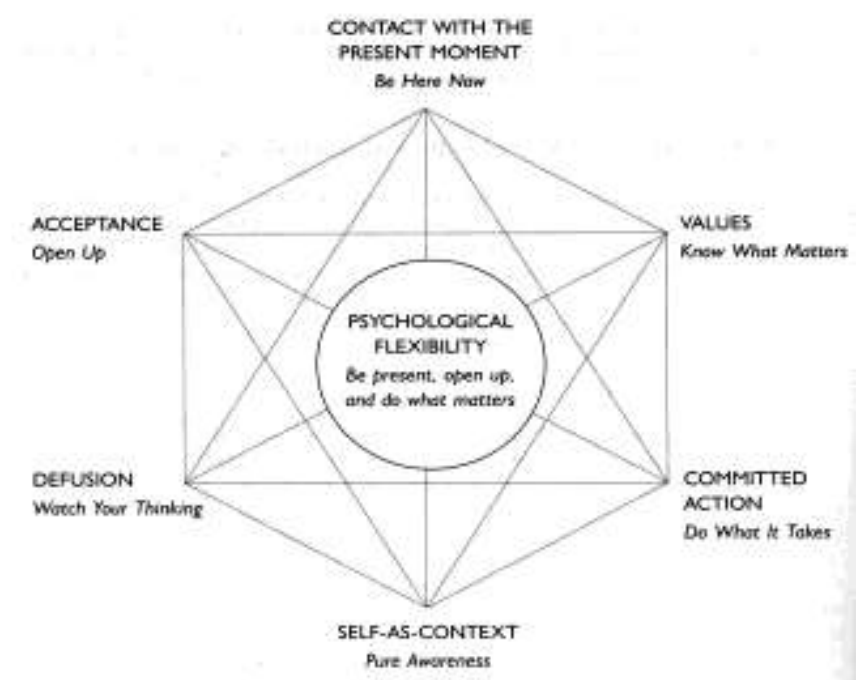

- Emotional intelligence of adolescents: analysis of emotional and behavioral problems, stressful life events and demographic characteristics Dangolia There was a positively significant relationship between the emotional intelligence of adolescents and their academic achievements, social functioning (activity). Stressful life events are positively related to stress management scores and negatively related to interpersonal, adaptability and general mood results"Social Work" ISSN online 2029-2775

* Emotional intelligence moderates the relationship between stress and mental health JosephCiarroch University students $(n=302)$ participated in a cross-sectional study that involved measuring life stress, objective and self-reported emotional intelligence, and mental health. Regression analyses revealed that stress, the important understanding the link between stress and mental health. https://doi.org/10.1016/S0191$\underline{8869(01) 00012-5}$

* KIMS; Baer, Smith, \& Allen,( 2004). Changes in the mental well beingcondition were correlated with increase in the social emotional intelligenceafter exposure to Acceptance commitment therapy

* Acceptance and commitment therapy for adolescents for improving social emotional intelligence -study protocol for a feasibility randomized controlled trial. Marcks \& Woods (2015) Acceptance and Commitment Therapy encourages acknowledgement and acceptance of mental experiences, increasing adolescents SEL and confirms that distress can be associated with an avoidance of experiencing uncomfortable thoughts and emotions. Samples were randomly allocated in groups to up to eight sessions (each 1 hour) of Acceptance Commitment Therapy. Results showed significant increase in the social emotional intelligence

* Acceptance and Commitment Therapy: A Transdiagnostic Behavioral Intervention for Mental Health and Medical Conditions. Dindo .L Van View (2016) ACT has been effectively implemented across a broad range of therapeutic settings, including mental health, primary care, and specialty medical clinics. ACT has also been delivered in a variety of formats, including 1-day group workshops and online sessions. To deliver ACT treatment to meet the unique needs of Adolescent populations helps to ensure treatment adherence and has foster successful application of ACT for adolescents.

The amygdale is responsible for the emotional mind whereas the prefrontal cortex is responsible for the thinking mind recent researchers suggest that though emotions and cognitions are separate entity occurring independently one influence and has the ability to control other productively. In this study the research has taken effort to improve the social emotional intelligence of adolescents by educating them about acceptance and commitment therapy thereby increasing the mental state leading to more productive life and minimizing the maturational crisis in later life

\section{Statement:-}

A study to determine the effectiveness of acceptance and commitment therapy on social emotional intelligence among adolescents at a selected institution

\section{Objective:-}

1. To assess the social and emotional intelligence among experimental and control group

2. To educate acceptance and commitment therapy for the experimental group

3. To reassess the post scores of social and emotional intelligence among experimental group 
4. To evaluate the effectiveness of acceptance and commitment therapy on social and emotional intelligence among experimental group

Research methodology:-

* Quantitative research approach

* True experimental design

* Sample size:50 samples EXP- 25 + CONTROL - 25

* Sampling technique: Stratified random sampling technique

- Population: Later Adolescents 17 - 19 years

* Setting: Selected educational institutions

Tools used:-

* Predesigned socio demographic schedule

* The Warwick-Edinburgh Mental Well-being scale

- Perceived stress scale

* Social emotional intelligence inventory

Major Findings:-

TAB 1:- To assess the social and emotional intelligence among experimental and control group

\begin{tabular}{|l|l|l|l|l|}
\hline & EXPERIMENTAL GROUP (25) & \multicolumn{2}{l|}{ CONTROL GROUP (25) } \\
\hline Level of emotional intelligence & No. of adolescents & $\%$ & No. of adolescents & \% \\
\hline $\begin{array}{l}\text { Area } \\
\text { for enrichment }\end{array}$ & $\mathbf{1 7}$ & $\mathbf{6 8 \%}$ & $\mathbf{1 8}$ & $\mathbf{7 2 \%}$ \\
\hline Effective functioning & $\mathbf{8}$ & $\mathbf{3 2 \%}$ & $\mathbf{7}$ & $\mathbf{2 8 \%}$ \\
\hline Enhanced skill & $\mathbf{0}$ & $\mathbf{0 . 0 \%}$ & $\mathbf{0}$ & $\mathbf{0 . 0 \%}$ \\
\hline Total & $\mathbf{2 5}$ & $\mathbf{1 0 0 . 0 \%}$ & $\mathbf{2 5}$ & $\mathbf{1 0 0 . 0 \%}$ \\
\hline
\end{tabular}

From the tab 1: majority of the samples both in the experimental and control group need the social emotional intelligence skills to be changed as the enhanced skill

Fig 2:-To determine the post test scores of social emotional intelligence, experimental and control group

\begin{tabular}{|c|c|c|c|c|c|c|}
\hline \multicolumn{10}{|c|}{ COMPARISON OF EXPERIMENT AND CONTROL GROUP SOCIAL AND EMOTIONAL } \\
INTELLIGENCE SCORE
\end{tabular}

When comparing the post test scores of the experimental and control group majority of the samples from the experimental group has enhanced social emotional intelligence. This shows the effectiveness of acceptance and commitment therapy on improvement of social emotional intelligence

\section{Conclusion:-}

Adolescents are the future pillars of the society, strengthening their coping and psychological flexibility through acceptance and commitment therapy improves their social emotional intelligence there by promoting the mental health and minimizing the stress makes the younger community more productive for the further life 


\section{References:-}

1. Stiffman Arlene R., Pescosolido Bernice A., Cabassa Leopoldo J. 2004. "Building a Model to Understand Youth Service Access: The Gateway Provider Model." Mental Health Services Research 6: 189-98 Google ScholarMedline

2. Stuart Heather, Julio Arboleda-Florez 2000. "Community Attitudes toward Persons with Schizophrenia." Canadian Journal of Psychiatry 46: 245-52 Google Scholar

3. Thoits Peggy A. 2005. "Differential Labeling of Mental Illness by Social Status: A New Look at an Old Problem." Journal of Health and Social Behavior 46: 102-19 Google ScholarAbstract

4. Child and Youth Emergency Mental Health Care (Unclaimed Children Revisited, Issue Brief No. 1) Modern Medicine, 2010

5. Section 2: An Overview of Federal Behavioral Health Funding Streams and Their Impact Modern Medicine, 2008

6. Treating Depressed Adolescents in Primary Care and Mental Health SettingsElizabeth McGann et al., Medscape, 2010 